\title{
Social Cartography for Social Innovation: A Design Approach
}

\author{
Miguel Navarro-Sanint \\ Universidad de Los Andes, Colombia \\ mi-navar@uniandes.edu.co
}

\begin{abstract}
In this paper I describe the use of social cartographies as a tool for design students in a social innovation process with communities. I show the process since the first approach to the communities until the end of the cartographic process and its outcomes. I present the advantages of using social cartographies when facilitating social innovation processes: the high involvement of the participants, how it helps to construct a common language, how it allows to understand the community and how it helped the design students to apprehend the tool for their design practice.
\end{abstract}

Keywords: Participatory design; Social Cartography; Social Innovation; Design tools.

\section{Introduction}

This paper presents the results of using Social Cartography as a tool for understanding communities from a designer's point of view with students from the Design for Communities course from the 4th semester of the bachelor in Design at the Universidad de Los Andes in Bogotá (Colombia). The purpose of this paper is not to present cartography as a map making profession, and it is not my intention to present a method on how to make good cartographies neither to present a teaching method to educate cartographers. This is about the use of cartography as a tool for participation by creating a physical space for discussion, similar to a Participatory Rural Appraisal (PRA) approach, that involves maps to "understand the community views on particular issues [with] the aim to engage local people in both the identification of problems and the design and implementation of solutions" (Murray et al., 2010, p.19); although, in this case, the students were encouraged to find dilemmas, instead of problems, to force the design team to see the complexity of the situation, as previous experiences have shown that when they try to find problems they usually find the symptoms and not the causes, and usually oversimplify the situation before understanding and analysing it.

\section{Why this Research?}

At the beginning of this research, the students of previous iterations of the same course used to work with interviews, mindmaps and infographics and the use of participatory tools was not being proposed as part of the 'observation' and 'frameworks' phases of design (Beckman and Barry, 2007, p.30). The abovementioned tools used nowadays are tools that are highly dependant on the interpretation of the designer and the result is usually highly subjective. This posed several issues in a participatory approach to communities. On one hand, the stakeholders did not recognise themselves in the resulting infographics and maps, and on the other hand, the design students tended to oversimplify the situation before analysing it. A tool that helps the design team to understand and analyse large amounts of information with the participation of the community was desirable. As social cartographies have been widely used in Colombia by anthropologists and social scientists (Andrade, 2001; Bastidas et al., 2008; Torres et al., 2012), this technique appeared as a potential tool to be added to the toolkit used by design practitioners when working with communities for social innovation in the Colombian context. What this research proposes is the use of Social Cartography by design students since an early stage of design studies, to facilitate their involvement with communities and to introduce them to tools that have been proved pertinent for social innovation by other practitioners from other disciplines.

\section{The Social Cartography as Part of a Social Innovation Method for Designers}

The method followed a social innovation approach composed by 6 stages: (1) diagnosing the target community, (2) proposing, (3) prototyping, (4) sustaining the design idea after its implementation, (5) scaling and spreading it, (6) to ultimately achieve a systematic change (Murray et al., 2010, p. 12); setting as goal for the first stage achieving a diagnosis of the problem and a framing of the situation, exposing the root causes of the problem and going beyond the symptoms (Murray et al., 2010). As one possible tool to achieve this, Murray et al. suggest the above mentioned PRA technique lying on the premise that people "are the best place to identify their own needs and express their own ideas of solutions" (Murray et al., 2010, p. 18). The principle behind this approach is to allow the design team to bring the stakeholders to the abstract side of the Beckman\&Barry's innovation process loop (Beckman \& Barry, 2007, p. 30) to make the community part of the analysis reducing the subjectivity and involving the community member in the recognition and 
management of their own conflicts. The final goal is to find dilemmas around a given topic, understanding dilemmas as a conflictive situation where there are many possible ways to manage the existing conflicts, but none is noticeable better than the other. Through dilemmas the students can reformulate conflictive situation, recognising, interrogating and contextualising it. This helps the design team to see the complexity of the situation and stimuli the community to work towards workable solutions (Murray et al., 2010, p. 14).

In this paper, only the first (1) stage of social innovation will be exposed as it is in this stage were the objective of social innovation and the use of social cartography converge, defining social cartography as an iterative process with three phases: (1) diagnosing the community, (2) producing the cartography and (3) giving back the cartography to the community (Habegger \& Mancila, 2006). In the cases that will be exhibited later, those three phases were conducted at least twice by each design team.

\section{The Project}

To start, each group of 4 students received a case based on a recent newspaper article with a copy of the article, e.g. 'Urban cyclists painted a bike lane on the 19th Avenue' (Tiempo, R. M. Z. E. , 2013, June,. Ciclistas urbanos pintaron un bicicarril en la Avenida 19. eltiempo.com. Bogotá). The duration of this stage was limited to 3 weeks. The first week, the students conducted observation and interviews to identify the stakeholders and places to start a process of framing the community according to their findings. The second week the students had to conduct the first iteration of the cartography. Finally, the third week, they had to conduct the second iteration of the cartography based on the previous one.

\section{The Cases}

Case 1 - Bike commuters: The starting point of this case was a group of bike commuters that started to paint their own bike lanes on the streets of Bogotá, responding to the written law that states that in case of absence of a bicycle lane, cyclists can ride on the right of the right lane of the road at no more than one meter from the sidewalk.

Case 2 - Longboarders: The starting point of this case was the rise of longboarding as a new sport in Colombia. Longboarders share the streets with cars as they lack of dedicated tracks for practicing the sport. They depend on each other for safety in a dangerous context.

Case 3 - Potentially dangerous dog's owners (PDD's owners): This case is based on a march organised by dog owners to ask for their dogs' rights under the slogan 'we are the voice of the voiceless'.

Each group faced the situation in a different way, depending on the accessibility and the availability of the people involved. The fact that the stakeholders share a space emerged as essential when planning participatory sessions and as a bias when selecting the participants for those sessions, influencing the future findings of the observation and framing. For case 1, the bike commuters that were painting the bike lanes were contacted trough Facebook by the design team, but they were unavailable and it was hard to set a meeting or even a face-to-face interview (a Facebook interview was conducted); so they decided to work with other people also involved in the situation: bike commuters, car commuters, public transportation commuters and pedestrians. For case 2, the longboarders were easy to reach, as they usually practice in a public park easily reachable from most of the residential places of the students and highly available, as they use to practice every Tuesday and Thursday afternoon, making planning easy; therefore, the selected participants for the cartography sessions were the previously mentioned longboarders, spectators of the longboarders (usually their friends) and car drivers with whom the longboarders share the road. For case 3 PDD's dog owners were easy to find in parks, but it was hard to find a time and a place to gather the participants, as it was hard to match the routine of the different PPD owners; consequently the design team chose PDD owners, dog owners (specifically those that do not own a PDD) and people who is afraid of dogs for different reasons, e.g. past experiences, small kids, trying to find availability through diversification of the stakeholders.

\section{A first approach to the community: from interviews to a set of stakeholders cards.}

Each design team started by conducting interviews with the people related to the previously stated situations. The result of those interviews was a set of cards with the different stakeholders (Figure 1). The information on the cards was composed by (1) an image of the stakeholder, (2) a quote from the interviews, (3) general information common to all, e.g. age, gender, location,etc. , (4) their interests, e.g. bike commuting, amateur longboarding, etc. and (5) their position about a specific topic, e.g. agreement with the dog restriction laws. Then, defining communities as groups of people interacting among them through diverse channels (internet, face-to-face,etc.) to share a common purpose (Gibson et al., 2009), the students used the cards to frame the community according to the interests stated on the cards, and trying always to identify the people that could provoke a discussion around a specific topic to expose the possible conflicts, e.g. a PDD's owner and a worried mother.

\section{Cartographies}

Having the cards as a provocation, the students gathered the stakeholders to start the cartography. With them, the students conducted two iterations. On the first iteration, none of the design teams achieved a detailed cartography as the participants were more interested on sharing ideas and thoughts than about creating a map involving the territory, but it served as a way to understand the community and their relation with the territory to 
then decide which kind of map should be used as a layout to start the second cartography.

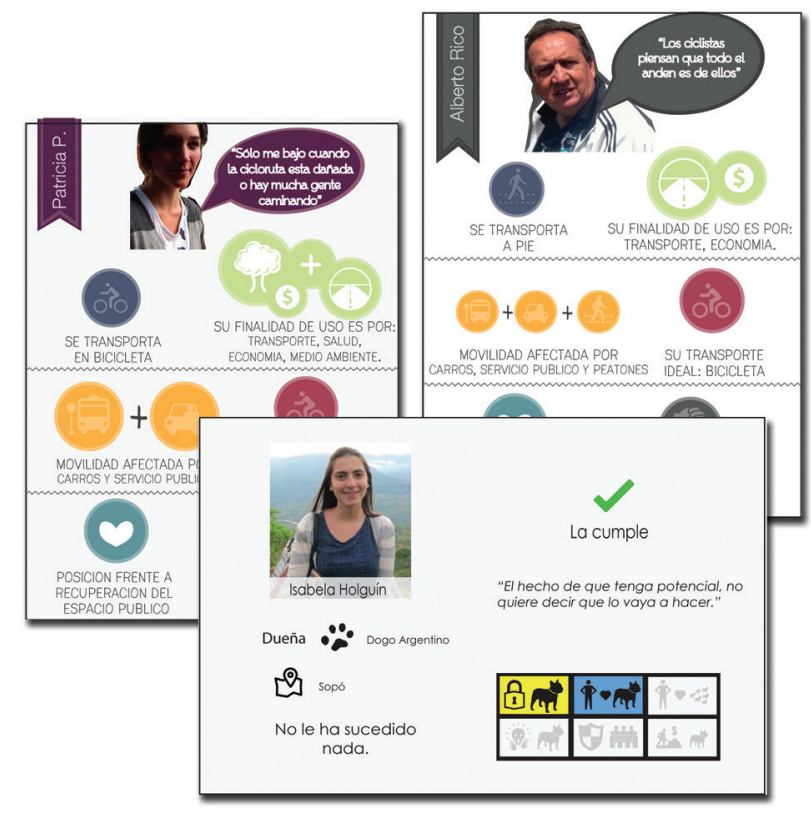

Figure 1: Stakeholders cards (Vecino-tello, 2013 ; Calderón-Parra, 2013)

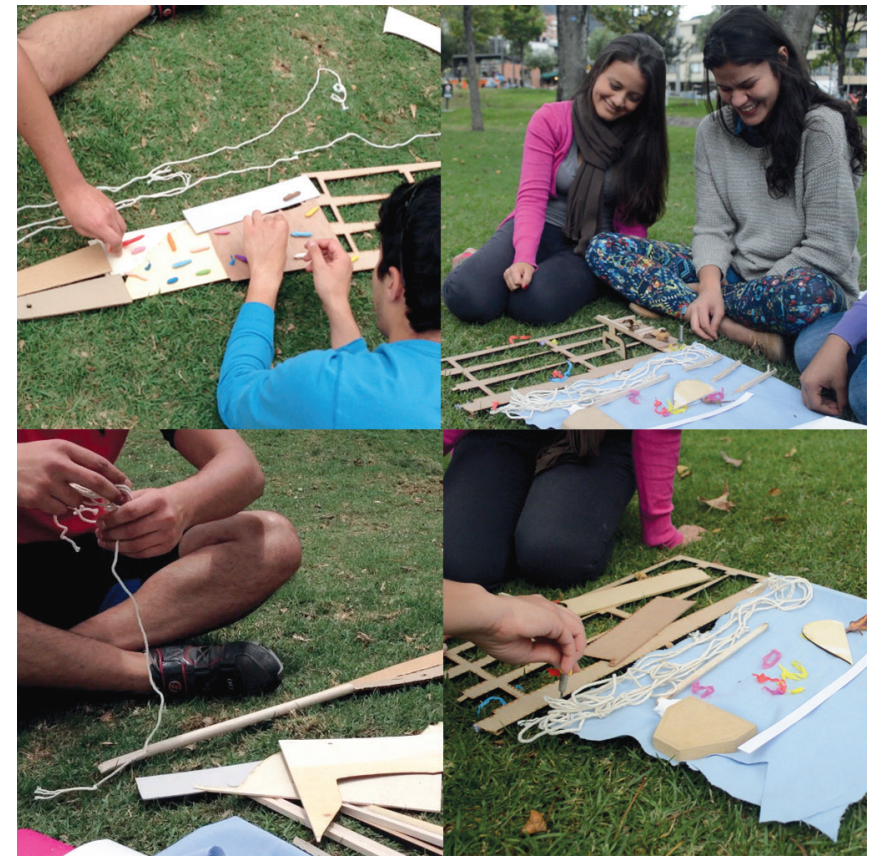

Figure 2: Participants mapping with tangible elements (Vecino-tello, 2013)

In case 1 (Bike commuters) the design team used a printed B1 sized street map of Bogotá as the base for the creation of the cartography and used a tracing paper layer on top to facilitate the participation of the stakeholders. The initial cartography helped the community to recognise the routes and routines of each one of the participants, and to identify the safe zones, unsafe zones, and conflictive zones and situations. For the second iteration, the design team tried to take the community to a more abstract level. They brought different materials, i.e. wood sticks, cardboard, ribbons, threads, etc. to the community and then used storytelling to provoke the participants to use the materials for mapping the dilemma represented by the following story: "Alexander uses his bike everyday as his mean of transportation. When he goes to the university he passes by some crowded streets full of pedestrians. One of them is Lucia, who goes to work by bus. Her mobility is restricted by the big amount of people that she has to share the sidewalk with. When she sees that there are no bikes using the bicycle lane, she decides to walk by it. When Alexander notices that the bike lane is being used by pedestrians, he decides to go by the car lane, putting himself on danger as he has to share the road with cars." (Vecino, 2013). The final result was a tangible map that represented the territory as a funnel that they are forced to cross (Figure 2).
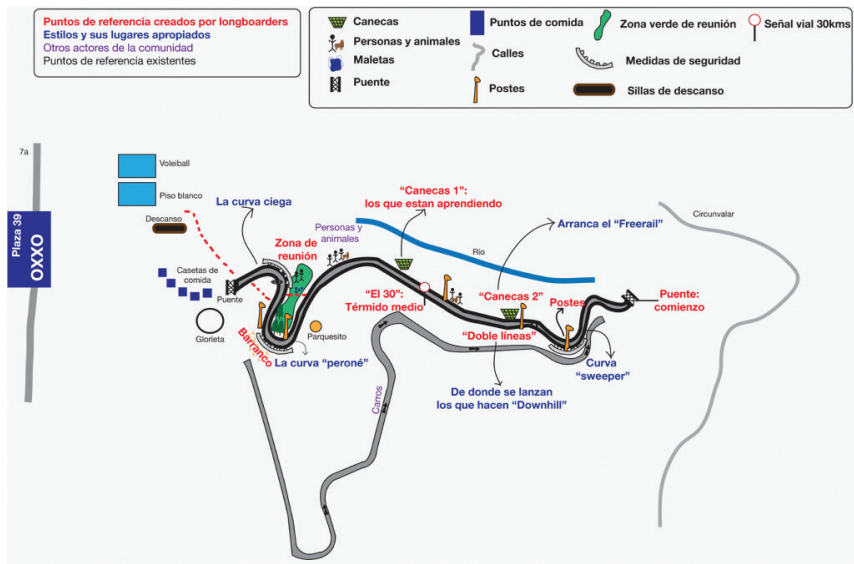

Figure 3: Social cartography of the longboarding territory (Varela, 2013)

In case 2 (longboarders) the students brought, for their first iteration, a blank B1 paper. The participants started to map their reality, each one of them thinking something different and expressing himself in a different way. As stated later by one of the students, this initial map was hard to understand: "First, we distributed some white sheets where each participant could freely express their thoughts about the community [...] We found out that each individual had his own thoughts and expressed himself in a different way, something that caused confusion when trying to understand the map" (Varela, 2013). For the same session the students decided to ask each member of the community to map on his own the activities of the community on a blank A4 sheets (Figure 5). For the second session, the students brought a map of the park where they usually practice the sport, given by the park administration. Based on that map the participants started to give a different meaning to each one of the elements presented on the initial map. Each part of the park they use has a special name according to iconic objects in the place (Figure 3), e.g. 'two bins' to refer to the place were Freerail starts; or according to things that happened on that place, e.g. the refer to one of the last curves of the road as 'the fibula curve' because, according to one of the longboarders, it is a place where many people fall to an open drain and brake their fibula bone. 


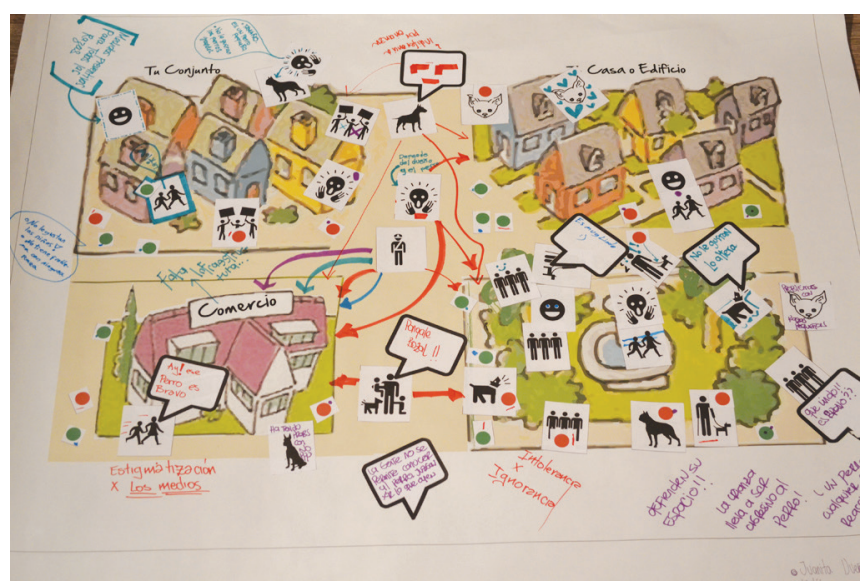

Figure 4: Social cartography around the potentially dangerous dogs dilemma (Calderón-Parra, 2013)

In case 3 (PDD's owners) the design team brought a B1 blank sheet of paper but the participants didn't start to map directly on the sheet. The design team started to write down the ideas that were being shared by the participants, getting a mind map. The conclusion of the observation from the first iteration of the cartography was that the participants were not recognising a common physical territory, but that they recognised common spaces in their neighbourhood: a house or apartment, a park, a commercial area. This led the design team to the use of stickers for the second cartography. The team decided to start the second iteration of the cartography with a basic layout showing common spaces: a gated community, an apartment/house area, a commercial area and a park, representing a neighbourhood. They also created the stickers, each one of them representing a different element found in a neighbourhood, e.g. dogs, families, groups of friends, etc. The result was a map of the social relations in the neighbourhood around PDD dilemmas (Figure 4), e.g. PDD's owners feel that their dog is not dangerous and try to defend the integrity of their dog, while people who fears dogs have already a prejudice about those dogs and do not trust the testimonies of the PDD's owner.

\section{Conclusions}

\section{A change in the role of the designer}

In this method the designer's role is proposed as the one of a facilitator and observer rather than the one of a communicator, as his task is to set the space and adjust the tools for the community to share their knowledge using drawings and objects to discuss diverse situations of concern for them. This change of role was evident in the response that each design team had when facing the participatory sessions, making decisions towards the creation of the elements that were going to provoke the participation of the community, rather than creating the maps, demonstrating the apprehension of the tool, e.g. the creation of the stickers instead of the creation of the map. Even if the previous experience of the students tended to make it challenging for them due to already learned paradigms about design, it was showed that that experience is also a good source for inspiration when facilitating processes.

\section{The involvement of the stakeholders}

The involvement of the stakeholders was clearly stated by one of the students when sharing a reflection about the cartography sessions: "it was noticeable during the cartographic process that the participants were more and more encouraged and started more discussions, got excited and agreed in some topics [...] the end many of them kept discussing and sharing new information" (Calderón-Parra, 2013) As she states, in all the projects the level of involvement increased on each iteration getting more involved with the project, finding themselves more represented by the cartographies and more able to interact with the gathered information and through it with other stakeholders.

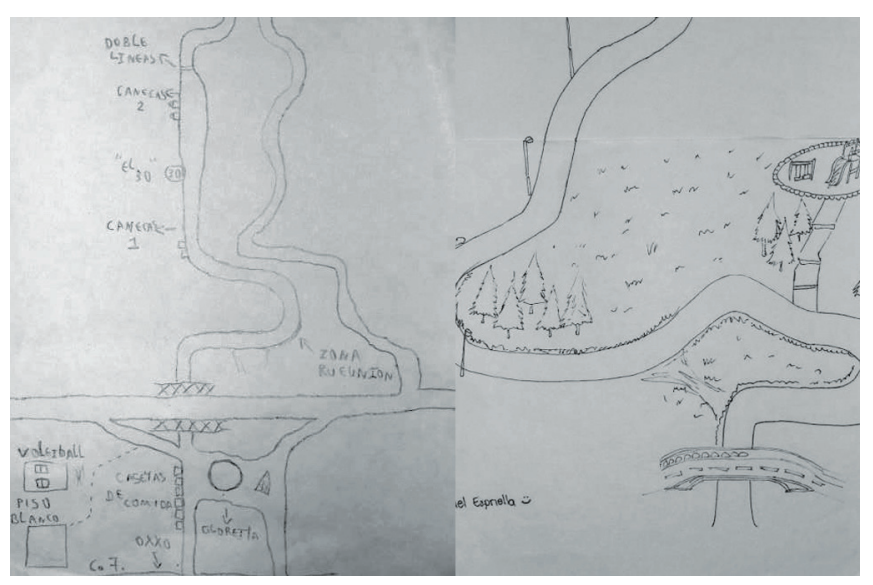

Figure 5: First iteration of cartographies (Varela, 2013)

\section{The construction of a common language}

The role of the designer as a facilitator is essential in this construction of a common language between the participants, because, as it was previously exposed, the restrictions set by the layout of the cartography frame the community in specific topics and create a background that contextualises the different ideas exposed by the participants so they can be understood and a meaning can be created. Therefore, the construction of this common language was facilitated by the design team by framing and was not done entirely by the community on its own. For example, on the second iteration of case 1, when the participants were constructing the abstract map of the story that they were previously told, the construction of a common language was evident when the different materials were given a meaning and all the participants were able to understand that meaning and built up recognising and respecting them (Figure 2), e.g. pieces of cardboard as roads. Here the framing of the meanings was achieved by the story that lied behind the map. This supports the idea of Moore\&Garzón (2010) that mapping "has the potential to develop critical consciousness and generate collective action because [...] participants develop their own language to describe 
their reality, producing terms and definitions that reflect their values." (p.66)

\section{Understanding the community}

The understanding of the community is done on three levels: (1) the understanding of the different stakeholders as part of the community, exposed by the longboarders on the first iteration of the cartography when mapping on their own sheet without any intervention of someone else; (2) the understanding of the community as a whole, shown by the second iteration of the cartographies and (3) the understanding of the community from the design team as an outsider. This last level is caused by the use of the social cartography as a tool, and is exposed by the reasoning done by each design team after each cartography and the accuracy of the proposed layouts and materials for subsequent iterations, that were successful on increasing the interaction of the participants with the information and with other participants, e.g. the use of the stickers by the PDD's owners case. A student when reflecting about her process describes the way this happens. She states that social cartography served to "favor the development of interactions and relationships that expose the different experiences, knowledge, roles, interests and positions that the participants have towards the situation." (Vecino-Tello, 2013).

Therefore, the use of social cartography as a tool for designers appears as a proper approach for achieving a high level of participation of the community in the design process, achieving also a high level of self-awareness and settling the foundations for social innovation with the support of the target community trough reflection, and perhaps, a higher chance of proposing social innovations that have a higher degree of success due to the active support of community members and stakeholders. Although, this tool also exposed an important limitation with the concept of territory as something more than what we see, as the space "inhabited by the memory and people's experiences" (Restrepo et al., 1998) This is not easily digested by the design team and the stakeholders, and turns the cartographic process into something hard when working with communities that do not share the same physical space, for example online communities.

\section{Acknowledgments}

Thanks to the students from the 4th semester of the bachelor in Design at the Universidad de Los Andes in Bogotá (Colombia) for their contribution, specially to those who were part of the cases presented on this paper. Thanks also to my coworkers who helped me develop the ideas here exposed.

\section{References}

Andrade, H. (2001). La cartografía social para la planeación participativa: experiencias de planeación con grupos étnicos en Colombia. Cali, $11 p$.

Bastidas, E. P., \& Gonzalez, C. A. (2008). Social cartography as a tool for conflict analysis and resolution: The experience of the AfroColombian community of Robles. Elena P. Bastidas and Carlos A. Gonzales, 1.

Beckman, S. L., \& Barry, M. (2007). Innovation as a learning process: Embedding design thinking. California Management Review, 50(1), 25.

Calderón-Parra, M. (2013). Reflexión cartografías, video perfiles y tarjetas de actores - Estudio 4. Unpublished manuscript, Departamento de Diseño, Universidad de Los Andes, Bogotá, Colombia.

Gibson, A. (2009). Social by Social (p. 120). Mute Publishing Ltd.

Habegger, S., \& Mancila, I. (2006). El poder de la Cartografía Social en las prácticas contrahegemónicas o La Cartografía Social como estrategia para diagnosticar nuestro territorio. Revista Araciega, 14.

Moore, E., \& Garzón, C. (2010). Social Cartography: The Art of Using Maps to Build Community Power. Race, Poverty \& the Environment, 17(2), 66-67.

Murray, R., Caulier-Grice, J., \& Mulgan, G. (2010). The Open Book of Social Innovation: Ways to Design, Develop and Grow Social Innovation (p. 222). NESTA

Torres, I. V., Gaona, S. R., \& Corredor, D. V. (2012). Cartografía social como metodología participativa y colaborativa de investigación en el territorio afrodescendiente de la cuenca alta del río Cauca. Cuadernos de Geografía, 21(2), 59-73.

Vecino-Tello, N. (2013). Texto Reflexivo - Estudio 4. Unpublished manuscript, Departamento de Diseño, Universidad de Los Andes, Bogotá, Colombia.

Varela, S. (2013). Reflexión cartografía social: Longboard - Estudio 4. Unpublished manuscript, Departamento de Diseño, Universidad de Los Andes, Bogotá, Colombia. 